\title{
A Typical Meteorological Year Generation Based on NASA Satellite Imagery (GEOS-I) for Sokoto, Nigeria
}

\author{
Olayinka S. Ohunakin, ${ }^{1}$ Muyiwa S. Adaramola, ${ }^{2}$ Olanrewaju M. Oyewola, ${ }^{3}$ \\ Richard L. Fagbenle, ${ }^{4}$ and Fidelis I. Abam ${ }^{5}$ \\ ${ }^{1}$ Mechanical Engineering Department, Covenant University, Ota, Ogun State, Nigeria \\ ${ }^{2}$ Department of Ecology and Natural Resources Management, The Norwegian University of Life Sciences, Ass, Norway \\ ${ }^{3}$ Department of Mechanical Engineering, University of Ibadan, Oyo State, Nigeria \\ ${ }^{4}$ Department of Mechanical Engineering, Obafemi Awolowo University, Ile-Ife, Nigeria \\ ${ }^{5}$ Department of Mechanical Engineering, Michael Okpara University of Agriculture, Umudike, Abia State, Nigeria
}

Correspondence should be addressed to Olayinka S. Ohunakin; olayinka.ohunakin@covenantuniversity.edu.ng

Received 20 October 2013; Accepted 10 February 2014; Published 17 March 2014

Academic Editor: Dionissios Mantzavinos

Copyright (C) 2014 Olayinka S. Ohunakin et al. This is an open access article distributed under the Creative Commons Attribution License, which permits unrestricted use, distribution, and reproduction in any medium, provided the original work is properly cited.

Computer simulation of buildings and solar energy systems are being used increasingly in energy assessments and design. This paper evaluates the typical meteorological year (TMY) for Sokoto, northwest region, Nigeria, using 23-year hourly weather data including global solar radiation, dew point temperature, mean temperature, maximum temperature, minimum temperature, relative humidity, and wind speed. Filkenstein-Schafer statistical method was utilized for the creation of a TMY for the site. The persistence of mean dry bulb temperature and daily global horizontal radiation on the five candidate months were evaluated. TMY predictions were compared with the 23-year long-term average values and are found to have close agreement and can be used in building energy simulation for comparative energy efficiency study.

\section{Introduction}

Energy remains the convergence point of most critical economic, environmental, and developmental issues confronting the world at the moment. Clean, efficient, stable, and sustainable energy services are ideal for global prosperity. Energy is paramount to achieving Nigeria's Vision $20: 2020$ needed by the country to be among the top 20 industrialized nations of the world. Lack of energy or its insufficiency in an economy is a potential source of social and economic poverty [1]. In general, a larger proportion of energy is found to be consumed in buildings in Nigeria as is the case in many countries. There is thus a growing concern about energy consumption in buildings and the attendant adverse impacts on the environment and with the increasing population and socioeconomic growth (as witnessed in Nigeria), building unit will continue to be a key energy intensive sector [2]. With the country's location on the tropics [3] (latitudes $4^{\circ} 1^{\prime}$ and $13^{\circ} 9^{\prime}$ North of the Equator and longitudes $2^{\circ} 2^{\prime}$ and $14^{\circ} 30^{\prime}$ East of the Greenwich Meridian), a large portion of the available energy is consumed on air conditioning. Energy consumption and electric load variation can be very sensitive to weather changes [1]. In Koyuncuolu [4], the unique load variation along with the highly increasing energy consumed for air conditioning called for immediate energy saving programs in which substantial savings can be achieved by decreasing the cooling or heating loads of buildings.

According to Jiang [5], an accurate prediction of building thermal performance relies very much on the weather data such as dry bulb temperature, relative humidity, wind speed, and solar radiation data. Energy simulation in buildings thus offers a valuable tool for engineers and architects to evaluate building energy consumption before the building is constructed; since weather conditions vary significantly from year to year due to the impact of climate change, there is a need to derive a customized weather data set that can well 
represent the long-term averaged weather conditions over a year which may be referred to as a typical year $[4,5]$. Forms of typical years include typical meteorological years (TMY), test reference year (TRY), and the weather year for energy calculations (WYEC). Typical weather year files like TMY are commonly used in building simulations to estimate the annual energy consumptions since analysis using a multiyear dataset is often not feasible and economical for the common design and analysis problems; representative days are too limited and often not accurate enough for a specific design and analysis problem [2]. The typical year approach can thus reduce the computational efforts in simulation and weather data handling by using one year instead of multiple years. However, in Skeiker and Abdul Ghani [6], the term "typicality" could be interpreted in many ways as used by several investigators, namely, (i) the selection of weather which appears to be typical of an appropriate portion of the year, (ii) selection of a year which appears to be typical from several years of solar radiation data, and (iii) some investigators having run long periods of observational data in an attempt to simulate typical weather for the calculation.

Several works have been carried out on the development of TMY for various locations worldwide (e.g., [714]) whereas in Nigeria, existing work on the generation of weather data may be limited to (i) TRY generation for Ibadan, (ii) TMY generation for Port Harcourt zone, and (iii) generation of a typical meteorological year for northeast, Nigeria $[1,15,16]$. The primary aim of this work is to generate TMY for Sokoto (located in North Nigeria with latitude$13.01^{\circ} \mathrm{N}$, longitude $-05.15^{\circ} \mathrm{E}$, and altitude $-350.8 \mathrm{~m}$ ) using a 23-year (1984-2006) hourly weather data from available satellite data acquired from NASA Geostationary Operational Environmental Satellite-1 (GEOS-1) Multiyear Time-Series Data. Figure 1 shows the studied site (Sokoto) and the other locations for which TMYs have been previously generated. Satellite and model-based products have been shown to be accurate enough to provide reliable solar and meteorological resource data over regions where surface measurements are sparse or nonexistent $[17,18]$. This advantage of wide GEOS1 data coverage has been utilized in the work of Dike et al., [19] for correlating meteorological estimates for seventeen locations within the southern region of Nigeria while Fadare [20] adopted the same dataset for modeling solar energy potential in Nigeria.

The selected weather data (including global solar radiation, dew point temperature, mean temperature, maximum temperature, minimum temperature, relative humidity, and wind speed) were chosen due to their impact on (and significant contribution to) the solar energy systems performance and heat gain and loss in buildings. For instance, in building applications, the knowledge of solar radiation is vital for accurate determination of cooling load in tropical regions (like Nigeria). It should also be noted that the air ambient temperature influences the thermal response of a building and the amount of heat gain and loss through it. The relative humidity is essential for the determination of latent heat for air-conditioning systems and evaporation levels. For solar energy conversion systems (Concentrated Solar Power and Photovoltaic systems), these meteorological data are also essential for design, selection, and performance evaluation of these systems.

\section{Materials and Method}

A TMY consists of 12 typical meteorological months (TMMs) selected from various calendar months in a multiyear weather database [5]. Several methods including Festa and Ratto, Danish and Sandia commonly exist for the development of TMY [21-23]. Sandia method is adopted in this work because of its wide applicability in the generation of weather data in tropical countries when compared with other methods [24]. However, Sandia procedure is difficult to implement directly in spite of its wide deployment in generating TMY [25]. In view of this, several procedures were described in literatures for generating TMY using Sandia method [13$15,25]$; this work employed the procedural steps developed and outlined in Sawaqed et al., [25] due to its simplicity, for the development of TMY for Sokoto.

In Sawaqed et al., [25], TMY development begins with the generation of typical meteorological month (TMM). The TMM procedure involves the selection of five candidate years that are closest to the composite of all the years under study for each of the 12 calendar months. The statistical analysis commenced with the generation of daily weather indices from the adopter parameters for each day of record. Each of the seven sets of daily indices is sorted into bins by month and they are used to establish 12 long-term cumulative distribution functions (CDFs) given by [25]

$$
\mathrm{CDF}_{j}=\frac{1}{n} j, \quad j=1,2, \ldots, n,
$$

where $j$ is ranked order number and $n$ is the total number of elements. A nonparametric method known as the Finkelstein-Schafer (FS) statistics [26] is then used to measure the closeness between the corresponding short-term and long-term CDFs as using (2) [26]:

$$
\mathrm{FS}_{j}=\frac{1}{n} \sum_{i=1}^{n} \delta_{i}, \quad i=1,2, \ldots, n,
$$

where $\delta_{i}$ is the absolute difference between the short-term and the long-term CDFs for day $i$ in the month, $n$ is the number of days in the month, and $j$ is the parameter (index) considered. For mean temperature $j=1$, for max temperature, $j=2$, and for solar flux $j=7$. For each of the candidate months, the seven different FS statistics calculated for the seven indices are grouped into a composite weighted index using (3) [25] together with the weighting factors listed in Table 1 . The resulting product gives the weighted sum (WS):

$$
\mathrm{WS}=\sum_{j=1}^{m} w_{j} \mathrm{FS}_{j},
$$

where $m$ is the number of indices (parameters/elements) considered, $W_{j}$ is the weight for index $j, \mathrm{FS}_{j}$ is the FS statistic for index $j$.

A weighting factor of 0.5 is assigned to global solar radiation while other weather indices were given equal 


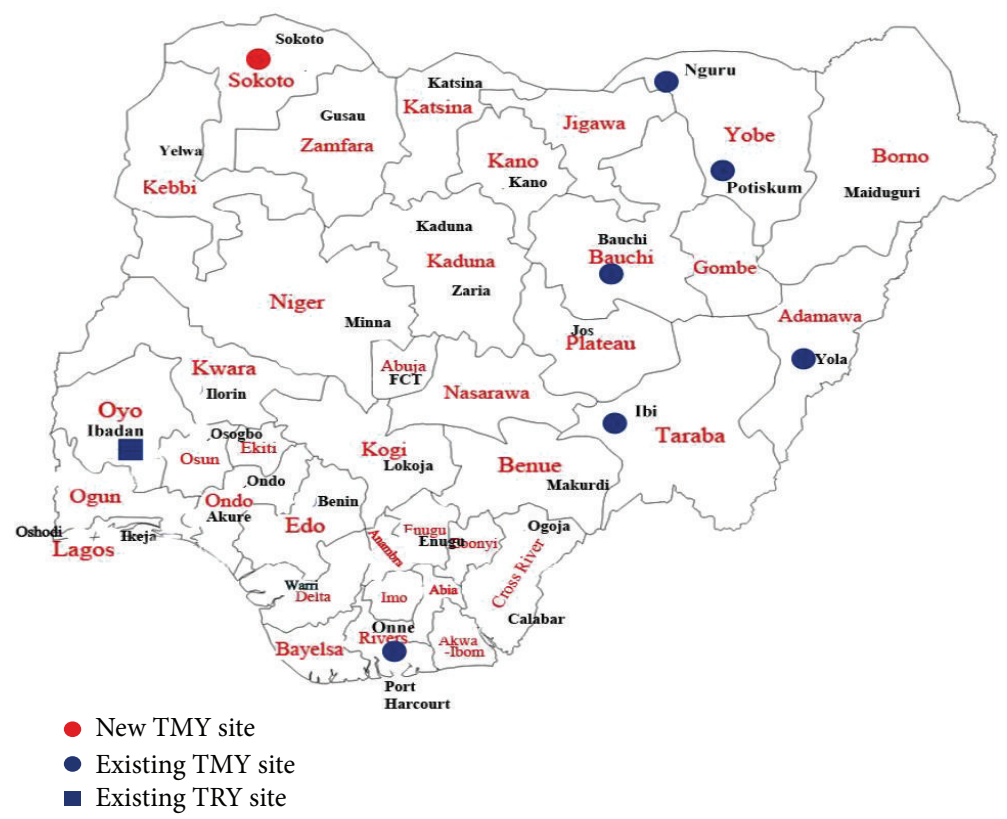

FIGURE 1: Map of Nigeria showing the studied site and locations with existing TMY values.

TABLE 1: Weighting factors of FS statistics.

\begin{tabular}{lc}
\hline Parameter & Weight $\left(w_{j}\right)$ \\
\hline DBT (minimum) & $1 / 12$ \\
DBT (maximum) & $1 / 12$ \\
DBT (mean) & $2 / 12$ \\
Dew point (mean) & $1 / 12$ \\
Relative humidity & $1 / 12$ \\
Solar radiation & $6 / 12$ \\
\hline
\end{tabular}

weights that add up to 0.5 . This is because (i) in tropical region with warm weather (like Nigeria), solar heat gain can be more significant in cooling load calculations for building as well as for passive and active heating systems and (ii) other weather parameters are directly or indirectly affected by global solar radiation.

All individual months are ranked in ascending order of the WS values. A typical month is then selected by choosing from among the five months with the lowest WS values by following the procedure developed by Sawaqed et al. [25]. The persistence of mean dry bulb temperature and daily global horizontal solar radiation are evaluated by determining the frequency and run length above and below fixed longterm percentiles. For mean daily dry bulb temperature, the frequency and run length above the 67 th percentile and below the 33rd percentile are determined. For global horizontal radiation, the frequency and run length below the 33rd percentile are also determined. The persistence data are used to select, from the five candidate months, the month to be used in the TMY. The highest ranked candidate month in ascending order of the WS values that meet the persistence criterion is used in the TMY.
The generated TMY values were compared with the long-term average values for the location under study. The performance of the TMY was investigated using methods of stochastic analysis to calculate the root-mean-square error (RMSE) given in (4) as expressed in Ohunakin et al. [27]:

$$
\operatorname{RMSE}=\left\{\frac{\left[\sum\left(H_{\text {pred }}-H_{\text {obs }}\right)^{2}\right]}{n}\right\}^{1 / 2} .
$$

\section{Results and Discussion}

In this work, the mean temperature and global solar radiation are used in selecting 12 typical meteorological months (TMMs) and together with the remaining parameters, TMY for Sokoto is developed. For each month, the FS statistic is also estimated for every year and for all of the six parameters that have been considered. For example, the FS statistics of global solar radiation for Sokoto is presented in Table 2. It can be observed from this table that the FS statistics show variation from one month to the other. Similar variation is also observed among other variables.

With the daily values of the selected parameters determined from the measured data, the values of the WS for each month of the 23-year period were then calculated as shown in Table 3. The five candidate years for each months having the lowest values of WS together with the corresponding year are all arranged in ascending order. The persistence of mean dry bulb temperature and daily global horizontal radiation on the five candidate months were evaluated by determining the frequency and run length above and below fixed percentiles (33rd and 67th) as discussed in [8]. The selected 12 TMMs are shown in Table 4. It can be seen that the 12 TMMs spread across the whole 23-year period; three TMMs are found in 
TABLE 2: FS statistics for global solar radiation.

\begin{tabular}{|c|c|c|c|c|c|c|c|c|c|c|c|c|}
\hline & Jan & Feb & Mar & Apr & May & Jun & $\mathrm{Jul}$ & Aug & Sept & Oct & Nov & Dec \\
\hline 1984 & 2.621 & 1.289 & 1.379 & 2.200 & 1.736 & 2.305 & 3.708 & 4.748 & 3.355 & 2.618 & 2.296 & 0.929 \\
\hline 1985 & 0.844 & 1.046 & 1.663 & 2.055 & 1.532 & 2.381 & 4.091 & 4.835 & 4.180 & 2.766 & 2.497 & 1.586 \\
\hline 1986 & 2.410 & 1.907 & 1.535 & 2.316 & 2.443 & 1.704 & 4.826 & 4.033 & 3.883 & 3.230 & 2.086 & 0.949 \\
\hline 1987 & 0.678 & 1.019 & 2.203 & 2.779 & 2.705 & 2.085 & 4.130 & 3.695 & 4.243 & 2.422 & 2.989 & 0.732 \\
\hline 1988 & 1.577 & 2.090 & 2.134 & 3.311 & 1.947 & 2.235 & 3.820 & 4.319 & 3.538 & 2.223 & 3.212 & 0.826 \\
\hline 1989 & 2.203 & 0.853 & 2.121 & 2.623 & 2.874 & 2.381 & 4.073 & 2.850 & 2.311 & 1.720 & 1.657 & 2.107 \\
\hline 1990 & 1.073 & 1.572 & 1.972 & 2.250 & 2.861 & 2.045 & 4.466 & 3.090 & 2.456 & 1.954 & 1.903 & 1.091 \\
\hline 1991 & 0.659 & 0.765 & 2.681 & 3.169 & 4.683 & 1.643 & 3.829 & 3.671 & 2.724 & 1.872 & 2.054 & 1.293 \\
\hline 1992 & 1.094 & 0.733 & 2.861 & 2.103 & 2.490 & 2.020 & 4.737 & 2.116 & 2.657 & 1.646 & 2.747 & 1.387 \\
\hline 1993 & 0.729 & 1.462 & 1.407 & 1.795 & 1.716 & 2.052 & 3.239 & 3.677 & 1.989 & 1.367 & 1.906 & 0.945 \\
\hline 1994 & 2.249 & 0.788 & 1.192 & 1.703 & 2.463 & 2.425 & 3.850 & 3.163 & 2.353 & 2.702 & 1.904 & 0.833 \\
\hline 1995 & 1.027 & 0.575 & 1.251 & 3.526 & 3.232 & 2.718 & 3.755 & 2.750 & 2.487 & 1.376 & 1.676 & 0.866 \\
\hline 1996 & 0.801 & 0.637 & 1.104 & 2.686 & 2.216 & 2.350 & 3.512 & 3.096 & 2.592 & 1.668 & 1.728 & 0.564 \\
\hline 1997 & 0.409 & 0.505 & 2.800 & 1.823 & 3.413 & 2.711 & 4.527 & 3.695 & 1.693 & 1.643 & 2.134 & 1.109 \\
\hline 1998 & 0.450 & 0.858 & 0.804 & 2.152 & 1.933 & 2.092 & 4.849 & 3.718 & 2.733 & 1.743 & 1.860 & 0.936 \\
\hline 1999 & 0.918 & 2.630 & 1.504 & 2.473 & 2.677 & 2.893 & 3.780 & 3.915 & 2.843 & 2.176 & 1.978 & 0.894 \\
\hline 2000 & 1.124 & 1.396 & 0.759 & 1.933 & 1.724 & 3.024 & 3.302 & 2.637 & 3.456 & 2.711 & 1.382 & 0.984 \\
\hline 2001 & 0.834 & 0.829 & 1.087 & 1.681 & 2.679 & 2.838 & 3.554 & 3.012 & 2.818 & 1.129 & 1.870 & 0.660 \\
\hline 2002 & 0.356 & 0.636 & 1.481 & 1.941 & 1.863 & 2.267 & 4.226 & 3.336 & 2.229 & 2.276 & 1.774 & 0.675 \\
\hline 2003 & 0.616 & 1.383 & 1.352 & 3.188 & 3.003 & 3.986 & 3.868 & 4.642 & 2.554 & 2.070 & 1.780 & 0.922 \\
\hline 2004 & 1.106 & 1.334 & 2.139 & 2.314 & 2.583 & 2.694 & 4.385 & 2.942 & 2.170 & 1.742 & 1.859 & 1.479 \\
\hline 2005 & 1.479 & 0.787 & 2.069 & 2.784 & 3.490 & 3.808 & 3.833 & 3.138 & 1.976 & 1.479 & 1.874 & 0.890 \\
\hline 2006 & 0.815 & 0.875 & 1.118 & 2.386 & 3.039 & 2.865 & 3.083 & 3.107 & 3.528 & 2.176 & 3.511 & 1.541 \\
\hline
\end{tabular}

TABLE 3: WS of FS statistics for the indices.

\begin{tabular}{|c|c|c|c|c|c|c|c|c|c|c|c|c|}
\hline & Jan & $\mathrm{Feb}$ & Mar & Apr & May & Jun & Jul & Aug & Sept & Oct & Nov & Dec \\
\hline 1984 & 1.770 & 1.383 & 1.958 & 3.499 & 4.219 & 2.908 & 2.641 & 2.853 & 2.661 & 4.273 & 2.147 & 1.026 \\
\hline 1985 & 1.497 & 1.636 & 3.620 & 2.924 & 4.466 & 3.087 & 2.896 & 2.870 & 2.753 & 2.645 & 1.701 & 1.332 \\
\hline 1986 & 1.739 & 1.874 & 3.180 & 3.665 & 4.167 & 2.606 & 3.370 & 2.559 & 2.920 & 3.529 & 2.725 & 1.198 \\
\hline 1987 & 0.984 & 1.155 & 3.121 & 3.891 & 4.124 & 2.520 & 2.609 & 2.461 & 2.845 & 3.400 & 1.823 & 1.075 \\
\hline 1988 & 1.666 & 1.656 & 2.696 & 3.842 & 3.500 & 2.861 & 2.799 & 2.959 & 2.816 & 2.569 & 2.128 & 1.350 \\
\hline 1989 & 2.222 & 1.387 & 2.392 & 2.617 & 4.599 & 2.585 & 2.493 & 1.871 & 1.457 & 2.533 & 1.368 & 1.838 \\
\hline 1990 & 1.606 & 1.488 & 2.669 & 2.918 & 3.928 & 2.427 & 2.934 & 1.969 & 1.625 & 2.640 & 1.559 & 2.274 \\
\hline 1991 & 0.965 & 2.406 & 2.339 & 3.160 & 5.363 & 1.978 & 2.662 & 2.321 & 2.487 & 1.896 & 1.534 & 1.201 \\
\hline 1992 & 1.834 & 1.234 & 2.468 & 2.521 & 3.855 & 2.561 & 3.094 & 1.612 & 2.472 & 2.968 & 2.101 & 1.313 \\
\hline 1993 & 1.448 & 1.356 & 2.195 & 2.711 & 2.953 & 2.620 & 2.545 & 2.516 & 1.579 & 2.388 & 1.685 & 1.125 \\
\hline 1994 & 2.143 & 1.286 & 1.683 & 1.901 & 3.316 & 4.386 & 2.914 & 1.952 & 1.773 & 1.919 & 1.812 & 1.265 \\
\hline 1995 & 1.541 & 0.971 & 1.575 & 3.137 & 3.987 & 2.716 & 2.594 & 1.817 & 1.635 & 1.460 & 1.657 & 1.483 \\
\hline 1996 & 1.091 & 1.179 & 1.520 & 2.855 & 3.068 & 2.102 & 2.234 & 2.014 & 1.491 & 2.036 & 1.756 & 0.989 \\
\hline 1997 & 0.854 & 1.482 & 2.996 & 2.538 & 3.238 & 2.584 & 2.995 & 2.465 & 1.588 & 1.670 & 1.856 & 1.271 \\
\hline 1998 & 1.331 & 1.129 & 2.139 & 2.732 & 2.615 & 2.464 & 3.165 & 2.417 & 2.351 & 3.473 & 1.477 & 1.365 \\
\hline 1999 & 1.150 & 2.538 & 2.412 & 2.272 & 2.822 & 3.843 & 2.467 & 2.766 & 2.106 & 2.173 & 1.416 & 1.120 \\
\hline 2000 & 1.748 & 1.746 & 1.898 & 1.746 & 2.581 & 3.245 & 3.109 & 2.124 & 2.337 & 2.383 & 1.476 & 1.276 \\
\hline 2001 & 1.364 & 1.326 & 1.939 & 2.719 & 2.929 & 2.610 & 2.483 & 1.978 & 1.953 & 2.242 & 1.650 & 1.048 \\
\hline 2002 & 0.896 & 1.267 & 1.918 & 1.944 & 2.634 & 3.756 & 3.024 & 2.019 & 1.613 & 2.893 & 2.116 & 1.245 \\
\hline 2003 & 1.326 & 2.269 & 2.196 & 3.378 & 4.278 & 3.043 & 2.414 & 2.911 & 2.131 & 1.989 & 1.860 & 1.273 \\
\hline 2004 & 1.456 & 1.640 & 3.125 & 2.288 & 3.106 & 3.559 & 4.508 & 3.703 & 3.197 & 3.095 & 1.851 & 1.498 \\
\hline 2005 & 1.998 & 2.289 & 2.962 & 2.570 & 3.477 & 3.474 & 2.697 & 2.929 & 2.655 & 2.338 & 1.475 & 1.260 \\
\hline 2006 & 1.840 & 1.782 & 2.088 & 3.455 & 3.227 & 2.842 & 2.034 & 2.189 & 2.708 & 4.470 & 2.413 & 1.436 \\
\hline
\end{tabular}


TABLE 4: Selected typical meteorological months.

\begin{tabular}{lc}
\hline Month & Year \\
\hline January & 2002 \\
February & 1992 \\
March & 2001 \\
April & 1999 \\
May & 1999 \\
June & 1996 \\
July & 1989 \\
August & 1994 \\
September & 1995 \\
October & 1996 \\
November & 2000 \\
December & 1996 \\
\hline
\end{tabular}

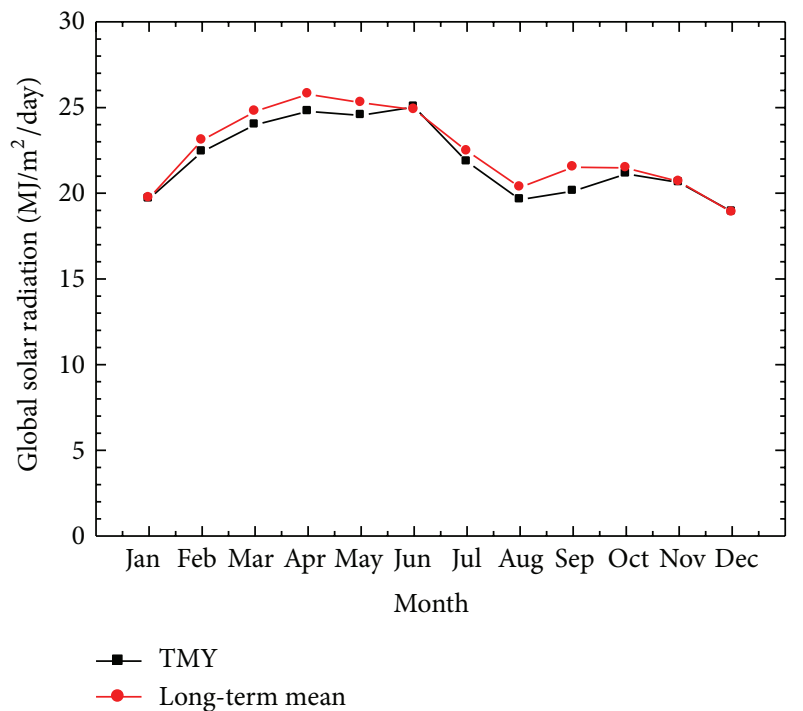

FIGURE 2: Predicted TMY with long-term average values for the global solar radiation.

1996 and two in 1999, whereas only one TMM exists in 1989, 1992, 1994, 1995, 2000, 2001, and 2002, respectively.

The relationship between the long-term mean and the TMY for selected weather parameters are presented in Figures $2-5$.

Figure 2 showed that good relationships exist between the long-term mean (23 year) and the TMY values for the global solar radiation, though with very small variations. It can be observed that the TMY and the long-term solar fluxes exceed $24 \mathrm{MJ} / \mathrm{m}^{2} /$ day from March to June with the peak as 25.1 and $25.8 \mathrm{MJ} / \mathrm{m}^{2} /$ day in June and April for the TMY and long-term fluxes, respectively. Figure 3 shows the monthly average mean temperature based on TMY and long-term values. It can be seen that Figure 3 follows similar trend with Figure 2. The peak values of the mean temperature are observed in April as 32.0 and $31.6^{\circ} \mathrm{C}$ for the TMY and long-term average values, respectively. The good agreement between TMY and longterm global solar radiation and mean temperature may be

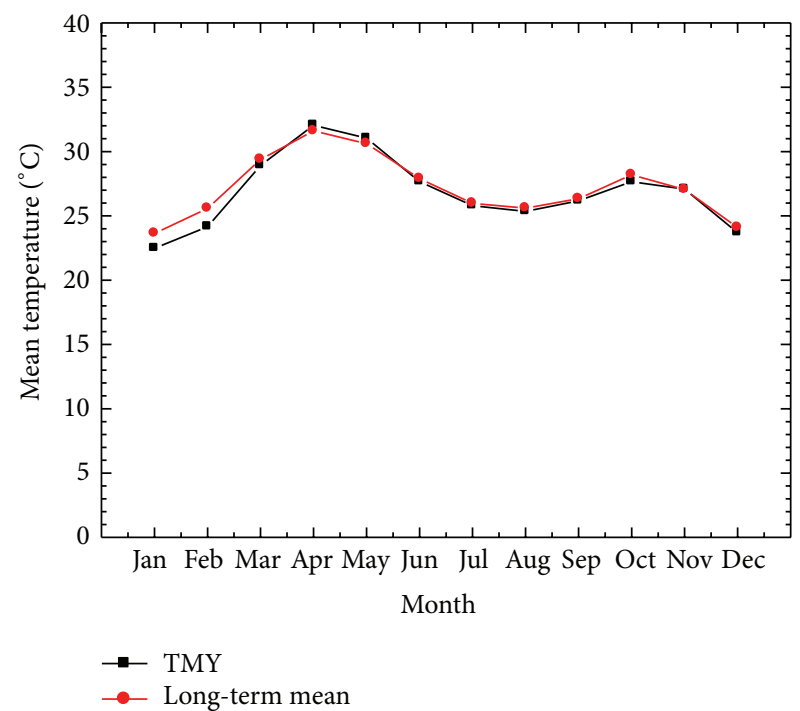

FIgURE 3: Predicted TMY with long-term average values for the mean temperature.

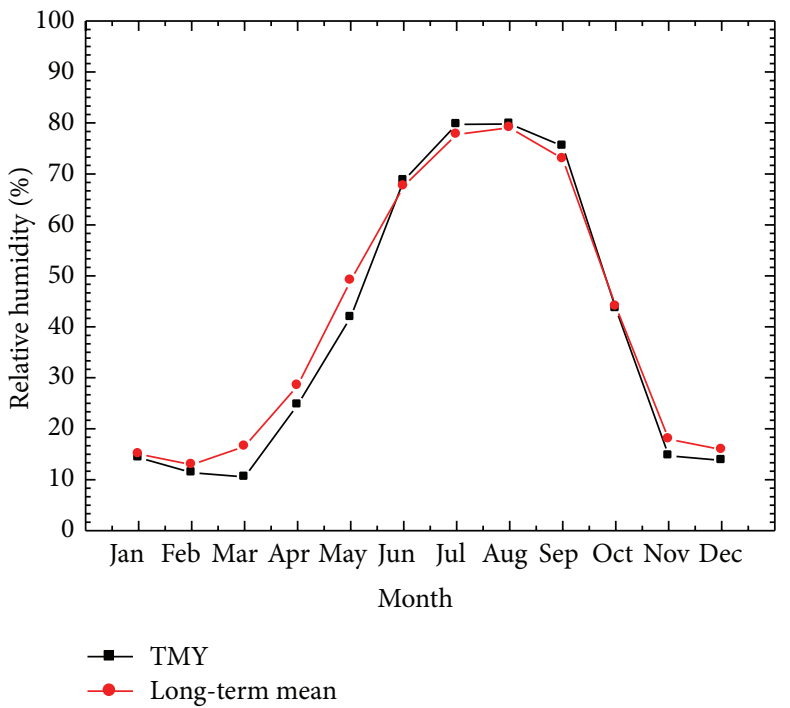

FIgURE 4: Predicted TMY with long-term average values for the relative humidity.

related to high weighting factor placed on each parameter being 0.5 for global solar radiation and 2/12 for mean temperatures (Table 1). The root-mean-square error (RMSE), which measures level accuracy between the TMY and longterm, is estimated as $0.62^{\circ} \mathrm{C}$ and $0.68 \mathrm{MJ} / \mathrm{m}^{2} /$ day for the mean temperature and global solar radiation. These low values further confirm good agreement between the TMY and longterm values for these parameters.

The relationship between the relative humidity (Figure 4) and dew point temperature (Figure 5) is reasonable but not as close as that for the global solar radiation and the mean temperature. The RMSE values for the relative humidity and dew point temperature are $3.23 \%$ and $2.04^{\circ} \mathrm{C}$, respectively. These values are relatively small, but higher than RMSE 


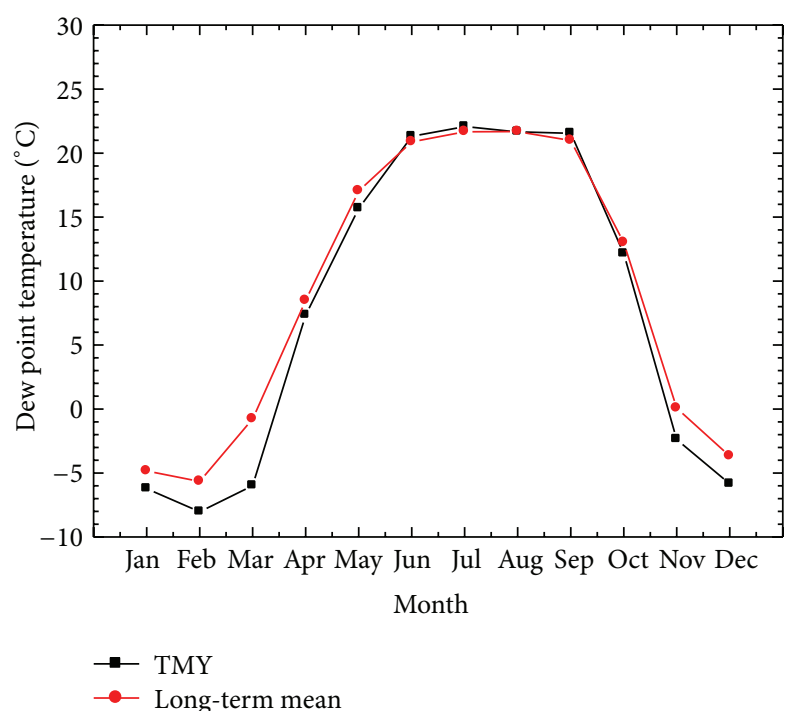

FIGURE 5: Predicted TMY with long-term average values for the dew point temperature.

values for the mean temperature and global solar radiation. This may be due to nonuniformity of the weighting factors and may also result from the fact that the selection of the TMMs is based on persistence of mean temperature and daily global horizontal radiation. Hence, the TMMs selected for the TMY can represent the long-term meteorological weather conditions for the Sokoto as considered in this study.

\section{Conclusions}

The TMY generated will be very useful for optimal design and evaluation of solar energy conversion systems, HVAC, and other solar energy dependent systems to be located within the vicinity of Sokoto. This work is a part of ongoing research work to develop a comprehensive TMY weather database for hourly building energy simulations in Nigeria and design of solar energy systems. In addition, the adopted satellite data have significantly advanced our ability to observe weather systems by providing frequent interval visible and infrared imagery of the earth surface, atmospheric moisture, and cloud cover that otherwise would have been impossible with ground observation. Findings based on the adoption of Filkenstein-Schafer statistical method utilized for the creation of a TMY for Sokoto show the following.

(i) The developed 12 TMMs are evenly spread across the whole 23-year period with three TMMs found in 1996 and two in 1999, and in 1989, 1992, 1994, 1995, 2000, 2001 , and 2002 only one exists.

(ii) The close fit observed in the values suggests a close agreement between the TMY predictions and longterm averages.

(iii) Observed agreement between TMY and long-term values of the respective fluxes may be related to weighting factor assigned to each parameter.

\section{Conflict of Interests}

The authors declare that there is no conflict of interests regarding the publication of this paper.

\section{Acknowledgment}

The authors are grateful to National Aeronautics and Space Administration (NASA) for making data for this study freely available.

\section{References}

[1] O. S. Ohunakin, M. S. Adaramola, O. M. Oyewola, and R. O. Fagbenle, "Generation of a typical meteorological year for north-east, Nigeria," Applied Energy, vol. 112, pp. 152-159, 2013.

[2] L. Yang, J. C. Lam, and J. Liu, "Analysis of typical meteorological years in different climates of China," Energy Conversion and Management, vol. 48, no. 2, pp. 654-668, 2007.

[3] O. S. Ohunakin, M. S. Adaramola, O. M. Oyewola, and R. O. Fagbenle, "Solar energy applications and development in Nigeria: drivers and barriers," Renewable and Sustainable Energy Reviews, vol. 32, pp. 294-301, 2014.

[4] H. Koyuncuolu, "Dynamic energy analysis in buildings," http://www.fbe.deu.edu.tr/ALL_FILES/Tez_Arsivi/2004/YL_ p1724.pdf.

[5] Y. Jiang, "Generation of typical meteorological year for different climates of China," Energy, vol. 35, no. 5, pp. 1946-1953, 2010.

[6] K. Skeiker and B. A. Ghani, "Advanced software tool for the creation of a typical meteorological year," Energy Conversion and Management, vol. 49, no. 10, pp. 2581-2587, 2008.

[7] D. Pissimanis, G. Karras, V. Notaridou, and K. Gavra, "The generation of a "typical meteorological year" for the city of Athens," Solar Energy, vol. 40, no. 5, pp. 405-411, 1988.

[8] A. Argiriou, S. Lykoudis, S. Kontoyiannidis et al., "Comparison of methodologies for TMY generation using 20 years data for Athens, Greece," Solar Energy, vol. 66, no. 1, pp. 33-45, 1999.

[9] S. A. M. Said and H. M. Kadry, "Generation of representative weather-year data for Saudi Arabia," Applied Energy, vol. 48, no. 2, pp. 131-136, 1994.

[10] J. C. Lam, S. C. M. Hui, and A. L. S. Chan, "A statistical approach to the development of a typical meteorological year for Hong Kong," Architectural Science Review, vol. 39, no. 4, pp. 201-209, 1996.

[11] Q. Zhang, J. Huang, and S. Lang, "Development of the typical and design weather data for Asian locations," Journal of Asian Architectural Building Engineering, vol. 1, no. 2, pp. 49-55, 2002.

[12] D. J. Thevenard and A. P. Brunger, "The development of typical weather years for international locations: part I, algorithms," ASHRAE Transaction, vol. 108, no. 2, pp. 376-383, 2002.

[13] D. J. Thevenard and A. P. Brunger, "The development of typical weather years for international locations: part II, production," ASHRAE Transaction, vol. 108, no. 2, pp. 480-486, 2002.

[14] Q. Zhang, J. Huang, and S. Lang, "Development of typical year weather data for Chinese locations," ASHRAE Transaction, vol. 108, no. 2, pp. 1063-1075, 2002.

[15] R. Layi Fagbenle, "Generation of a test reference year for Ibadan, Nigeria," Energy Conversion and Management, vol. 36, no. 1, pp. 61-63, 1995. 
[16] C. O. C. Oko and O. B. Ogoloma, "Generation of a typical meteorological year for port harcourt zone," Journal of Engineering Science and Technology, vol. 6, no. 2, pp. 204-221, 2011.

[17] SSE6 Methodology, "Surface meteorology and solar energy, (SSE) release 6.0 methodology," https://eosweb.larc.nasa.gov/ cgi-bin/sse/sse.cgi?+s01+s05+s06\#s05.

[18] O. S. Ohunakin, Fluid dynamics modelling of the impact of climate change on solar radiation in Nigeria [Ph.D. thesis], 2013.

[19] V. N. Dike, T. C. Chineke, O. K. Nwofor, and U. K. Okoro, "Evaluation of horizontal surface solar radiation levels in southern Nigeria," Journal of Renewable and Sustainable Energy, vol. 3, no. 2, Article ID 023101, 2011.

[20] D. A. Fadare, "Modelling of solar energy potential in Nigeria using an artificial neural network model," Applied Energy, vol. 86, no. 9, pp. 1410-1422, 2009.

[21] I. J. Hall, R. R. Prairie, H. E. Anderson, and E. C. Boes, "Generation of typical meteorological year for 26 SOLMET stations," Sandia Laboratories Report SAND 78-1601, Sandia Laboratories, Albuquerque, NM, USA, 1978.

[22] H. Lund and S. Eidorff, Selection Methods for Production of Test Reference Years, Appendix D, Contract 284-77 ES DK, Report EUR, Commission of the European Communities, 1980.

[23] R. Festa and C. F. Ratto, "Proposal of a numerical procedure to select reference years," Solar Energy, vol. 50, no. 1, pp. 9-17, 1993.

[24] S. Janjai and P. Deeyai, "Comparison of methods for generating typical meteorological year using meteorological data from a tropical environment," Applied Energy, vol. 86, no. 4, pp. 528537, 2009.

[25] N. M. Sawaqed, Y. H. Zurigat, and H. Al-Hinai, "A step-by-step application of Sandia method in developing typical meteorological years for different locations in Oman," International Journal of Energy Research, vol. 29, no. 8, pp. 723-737, 2005.

[26] J. M. Filkenstein and R. E. Schafer, "Improved goodness-of-fit tests," Biometrika, vol. 58, no. 3, pp. 641-645, 1971.

[27] O. S. Ohunakin, M. S. Adaramola, O. M. Oyewola, and R. O. Fagbenle, "Correlations for estimating solar radiation using sunshine hours and temperature measurement in Osogbo, Osun State, Nigeria," Frontiers in Energy, vol. 7, no. 2, pp. 214222,2013 

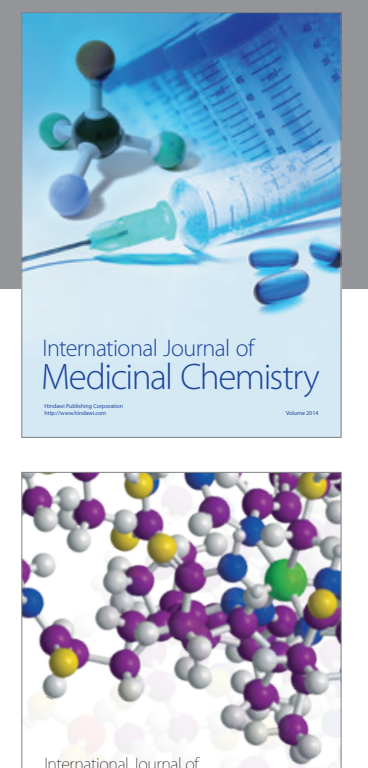

\section{Carbohydrate} Chemistry

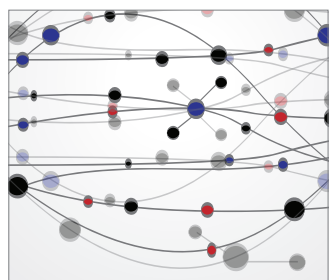

The Scientific World Journal
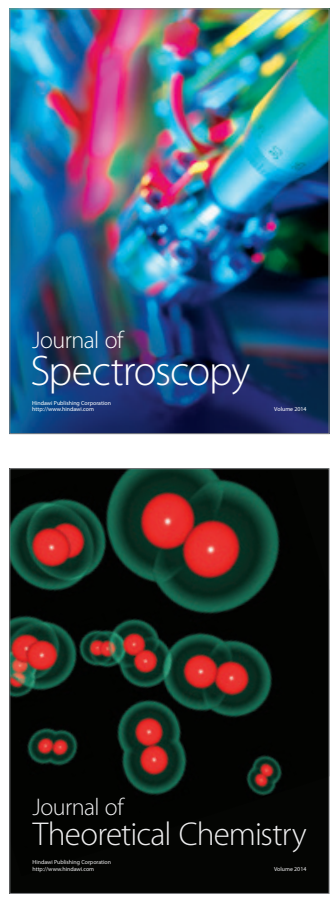
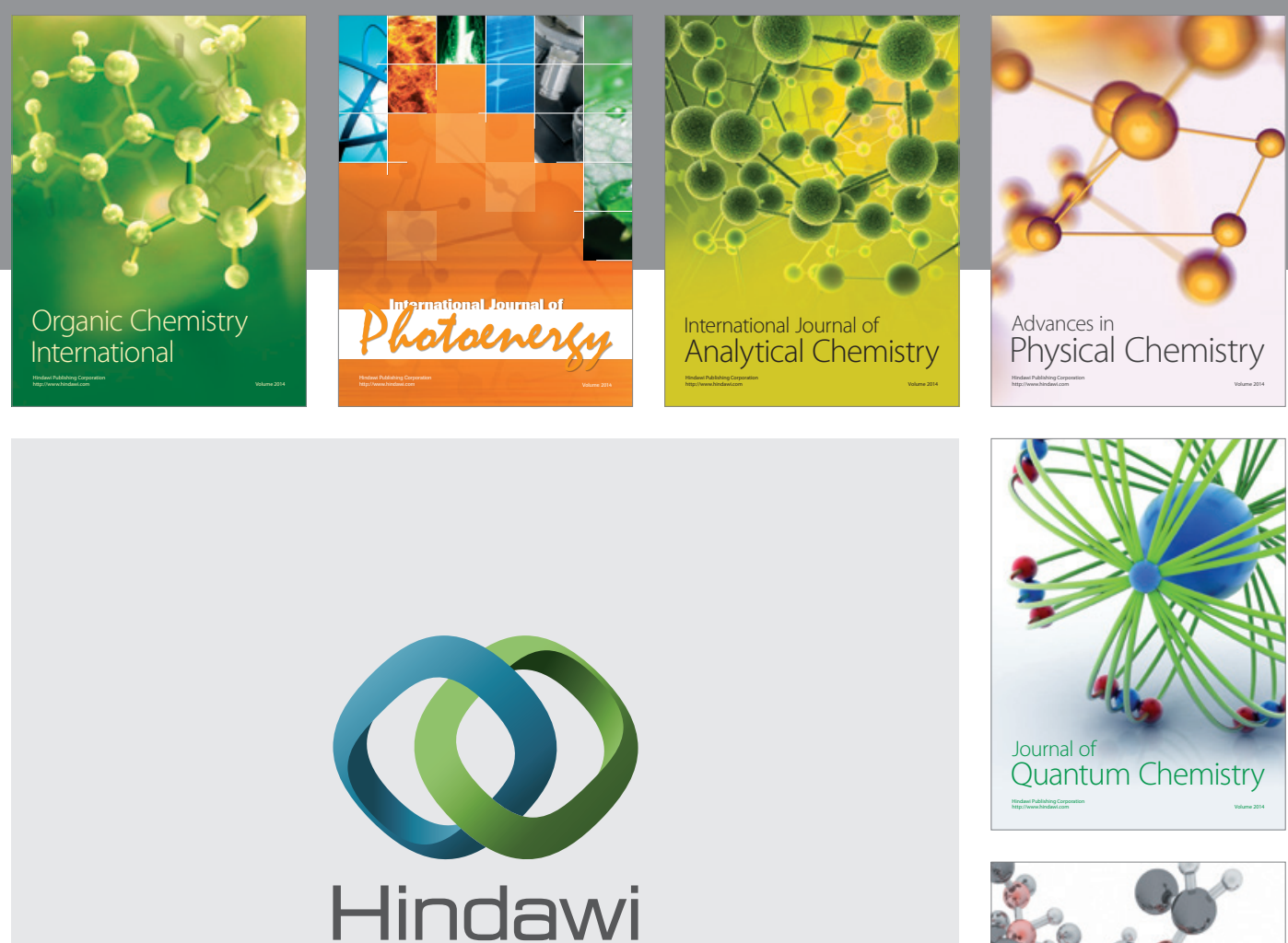

Submit your manuscripts at

http://www.hindawi.com

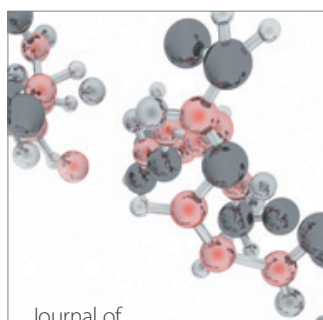

Analytical Methods

in Chemistry

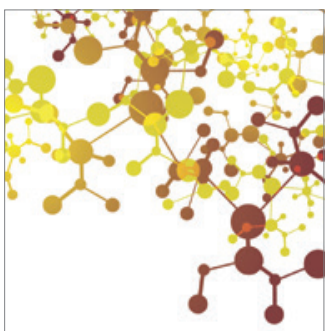

Journal of

Applied Chemistry

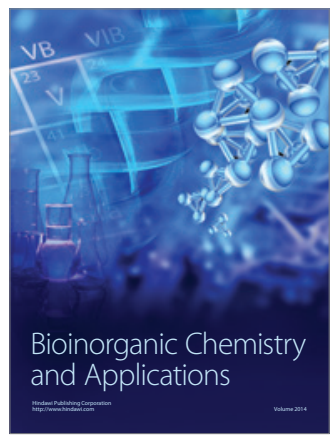

Inorganic Chemistry
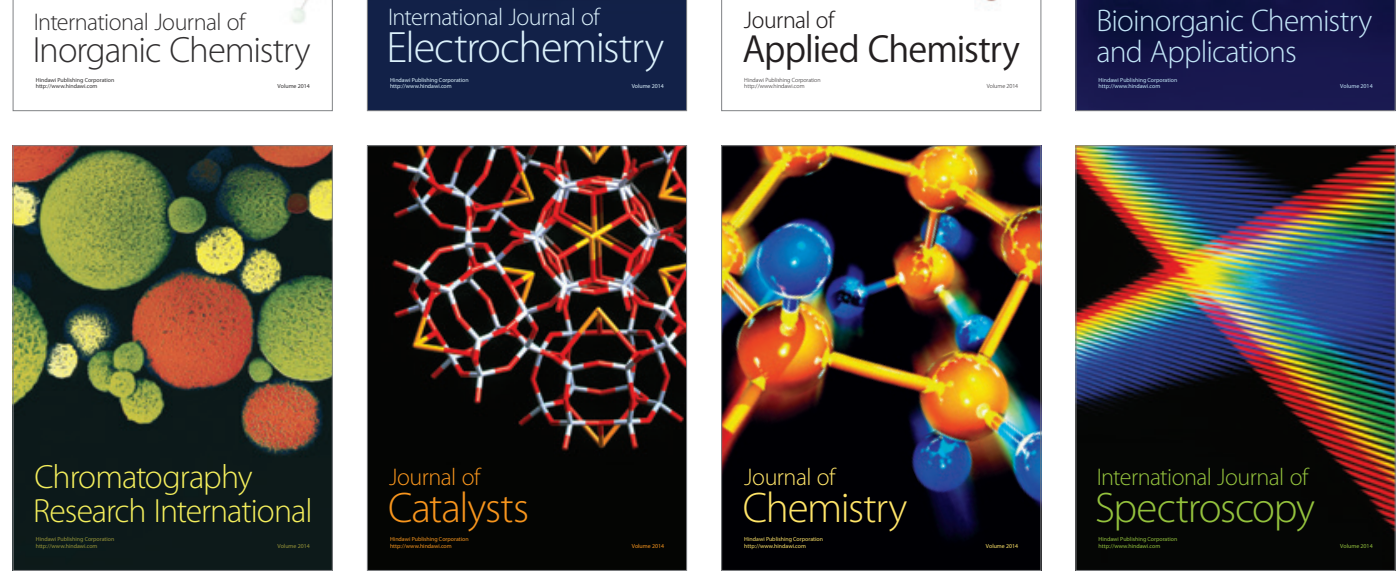